Chapman University

Chapman University Digital Commons

9-10-2013

\title{
Patterns of Senescence in Human Cardiovascular Fitness: Vo2 Max in Subsistence and Industrialized Populations
}

\author{
Anne C. Pisor \\ University of California, Santa Barbara \\ Michael Gurven \\ University of California, Santa Barbara \\ Aaron D. Blackwell \\ University of California, Santa Barbara \\ Hillard Kaplan \\ Chapman University, hkaplan@chapman.edu \\ Gandhi Yetish \\ University of New Mexico
}

Follow this and additional works at: https://digitalcommons.chapman.edu/esi_pubs

Part of the Biological and Physical Anthropology Commons, Economic Theory Commons, Ethnic Studies Commons, Latin American Studies Commons, Other Anthropology Commons, Other Economics Commons, and the Social and Cultural Anthropology Commons

\section{Recommended Citation}

Pisor, A. C., Gurven, M., Blackwell, A. D., Kaplan, H., \& Yetish, G. (2013). Patterns of senescence in human cardiovascular fitness: VO2 max in subsistence and industrialized populations. American Journal of Human Biology, 25(6), 756-769. https://doi.org/10.1002/ajhb.22445 


\title{
Patterns of Senescence in Human Cardiovascular Fitness: $\mathrm{VO}_{2} \max$ in Subsistence and Industrialized Populations
}

\author{
Anne C. Pisor ${ }^{1,{ }^{,}, \text {Michael Gurven }}{ }^{1}$, Aaron D. Blackwell ${ }^{1}$, Hillard Kaplan $^{2}$, and Gandhi \\ Yetish $^{2}$ \\ ${ }^{1}$ Department of Anthropology, University of California, Santa Barbara, California \\ 2Department of Anthropology, University of New Mexico, Albuquerque, New Mexico
}

\begin{abstract}
Objectives-This study explores whether cardiovascular fitness levels and senescent decline are similar in the Tsimane of Bolivia and Canadians, as well as other subsistence and industrialized populations. Among Tsimane, we examine whether morbidity predicts lower levels and faster decline of cardiovascular fitness, or whether their lifestyle (e.g., high physical activity) promotes high levels and slow decline. Alternatively, high activity levels and morbidity might counterbalance such that Tsimane fitness levels and decline are similar to those in industrialized populations.
\end{abstract}

Methods-Maximal oxygen uptake $\left(\mathrm{VO}_{2} \mathrm{max}\right)$ was estimated using a step test heart rate method for 701 participants. We compared these estimates to the Canadian Health Measures Survey and previous studies in industrialized and subsistence populations. We evaluated whether health indicators and proxies for market integration were associated with $\mathrm{VO}_{2}$ max levels and rate of decline for the Tsimane.

Results-The Tsimane have significantly higher levels of $\mathrm{VO}_{2}$ max and slower rates of decline than Canadians; initial evidence suggests differences in $\mathrm{VO}_{2}$ max levels between other subsistence and industrialized populations. Low hemoglobin predicts low $\mathrm{VO}_{2} \mathrm{max}$ for Tsimane women while helminth infection predicts high $\mathrm{VO}_{2}$ max for Tsimane men, though results might be specific to the $\mathrm{VO}_{2}$ max scaling parameter used. No variables tested interact with age to moderate decline.

Conclusions-The Tsimane demonstrate higher levels of cardiovascular fitness than industrialized populations, but levels similar to other subsistence populations. The high $\mathrm{VO}_{2} \max$ of Tsimane is consistent with their high physical activity and few indicators of cardiovascular disease, measured in previous studies.

Physical fitness, or the ability to perform "daily tasks [...] without undue fatigue" (Centers for Disease Control and Prevention, 2011), declines with age in both humans and nonhuman animals [e.g., dogs, (Haidet, 1989); horses (Walker et al., 2010)]. In humans, even elite athletes exhibit physical fitness declines (Sagiv et al., 2007) and these declines from higher

(C) 2013 Wiley Periodicals, Inc.

"Correspondence to: Anne C. Pisor, Department of Anthropology, University of California, Santa Barbara, CA 93106-3210, USA. pisor@umail.ucsb.edu.

Additional Supporting Information may be found in the online version of this article. 
peak fitness may be steeper than the decline of their more sedentary counterparts (Fitzgerald et al., 1997). Although the decline in physical fitness appears universal in industrialized nations (Fitzgerald et al., 1997; Hawkins and Wiswell, 2003), an outstanding question is whether similar declines are observed in subsistence level populations. Individuals in subsistence populations often engage in physically demanding work well into old-age, yet these populations also often carry high burdens of pathogens and parasites, which may result in conditions that limit physical capacity, such as anemia (Benefice and Ndiaye, 2005; Panter-Brick et al., 1992). As a consequence, age related decline in physical fitness may be accelerated in subsistence populations due to systemic stress and disease or decelerated due to high demand for physical capacity. Alternatively, decline may be similar to those observed in industrialized populations if senescence in physical fitness follows a speciestypical pattern. This article: (1) investigates age-related decline in cardiovascular fitness-a component of physical fitness determined by oxygen transport and use-in a subsistence population, the Tsimane of Bolivia; (2) examines factors mediating cardiovascular fitness, including anemia, physical condition, and market integration; and (3) compares the rates of decline in the Tsimane with those of an industrialized nation to explore whether both exhibit similar patterns of decline.

Although other factors contribute to physical fitness, individual fitness is determined primarily by the cardiovascular system, and in particular cardiac output (American College of Sports Medicine, 2006; Sagiv et al., 2007). The key molecule in this larger system is oxygen, which allows the conversion of adenosine triphosphate to available energy in muscle cells (Wagner, 1996). Thus, we quantify cardiovascular fitness by estimating the maximum volume of oxygen an individual is able to use per minute, often called aerobic capacity $\left(\mathrm{VO}_{2}\right.$ max; Howley et al., 1995; Wagner, 1996). The cardiovascular system is flexible in its development, responding to features of an individual's early environment (Rowland and Boyajian, 1995) such as fetal testosterone exposure (Manning et al., 2007) and the elevation above sea level experienced during childhood (Frisancho et al., 1995). In populations where food production, processing, childcare, and other daily tasks require high levels of physical activity, early demand may favor early investment in oxygen transport function, leading to greater peak cardiovascular fitness (e.g., Frisancho et al., 1995; Malina, 2001). Additionally, cardiovascular fitness may remain high if high levels of activity are sustained throughout adulthood, or may be up-regulated by training (Finch and Lenfant, 1972; Hoffman, 2002; Sagiv et al., 2007; Wagner, 1996), leading to slower decline with age.

In subsistence populations, individuals experience high energy demand in conjunction with both work and leisure activities (e.g., Malina and Little, 2008; Panter-Brick et al., 1992; Walker and Hill, 2003). It appears that any differences in physical fitness performance may arise from differences in levels of sedentary activity between subsistence and industrialized populations: as subsistence groups integrate to national markets, sedentism may increase, leading to reductions in cardiovascular fitness (Katzmarzyk et al., 1994; Rode and Shephard, 1994). However, studies employing factorial methods, accelerometry, and doubly labeled water suggest considerable overlap in measured activity levels and energy expenditure among members of subsistence and industrialized populations (Gurven et al., 2013; Madimenos et al., 2011; Pontzer et al., 2012). Among the Tsimane, our focal group, women age 20-70 have average physical activity levels (PALs, defined as total daily energetic 
expenditure divided by basal metabolic rate) of $1.73-1.85$ over a $24 \mathrm{~h}$ period (Gurven et al., 2013) while a same age, nonoverweight American sample has a similar average of 1.78 (Blair et al., 2004). Tsimane men are more physically active than their American counterparts (Tsimane males: 2.02-2.15, American males: 1.73), though both American and Tsimane males fall within the range of cross-population PALs reported by Gurven et al (2013).

The few studies that have examined cardiovascular fitness in subsistence populations show mixed evidence for a decline in fitness with age. Turkana men engaging in pastoralism do not exhibit a consistent decline in $\mathrm{VO}_{2} \mathrm{max}$ by age 45 (Curran-Everett, 1994). Ache women living on a reservation and practicing a combination of gathering and horticulture do not exhibit a decline in cardiovascular fitness by age 60 (Walker and Hill, 2003). However, these findings are based on relatively small samples and may be unduly influenced by outliers. In contrast, Inuit still living a traditional lifestyle do show significant declines with age (Shepard, 1978), as do small-scale farmers in Kenya (Christensen et al., 2012). Given these mixed results, should we expect a cardiovascular fitness decline in all subsistence level societies, and if so, of the same steepness as the decline among industrialized nations?

Although sustained subsistence activity, muscularity, and leanness should help promote cardiorespiratory fitness throughout life, other features of subsistence societies may instead hinder performance, especially at later ages. Cardiovascular fitness level may be curbed by limited energy reserves and food shortages. The benefits of a large capacity for physical activity may be age specific: investments in cardiovascular fitness may be high early in the lifespan, however higher adult mortality in subsistence societies may discount investments that maintain functionality in old age. Limited energy budgets in subsistence societies might make such tradeoffs between adult functionality and late age maintenance more severe. Even in industrialized societies, the diminished ability to maintain muscle with age results in lower muscle mass, or sarcopenia. Although central limiting factors, such as cardiac output, are primarily responsible for age-related decline (Carrick-Ranson et al., 2013; Ogawa et al., 1992), muscle mass is also a predictor of slowed decline (Carrick-Ranson et al., 2013; Sanada et al., 2007; Stones and Kozma, 1985), as muscles consume 95\% of oxygen used by the body during exercise (Fleg and Lakatta, 1988).

Another physical limit on the transport system is imposed by hemoglobin-bearing red blood cells, which carry oxygen from lungs to muscles. Individuals with anemia (low hemoglobin) do worse than nonanemic individuals on cardiovascular fitness tests (Buzina et al., 1989; Panter-Brick et al., 1992; Wagner, 1996), as do individuals who experience blood loss from chronic helminth infections (King et al., 2005; Panter-Brick et al., 1992). Anemia and helminth infections are more common in subsistence populations than industrialized populations (Hotez et al., 2008). The Tsimane have a much higher prevalence of both helminths (Blackwell et al., 2011) and anemia than North Americans do. Giardia and other protozoal, bacterial, and viral infections are also prevalent (Blackwell et al., 2013).

Likewise, respiratory ailments curb oxygen uptake (Collins, 1999; Wagner, 1996) and are often common in subsistence groups. While asthma and allergies are prevalent in the United States (Sondik et al., 2012), tuberculosis, pneumonias, and upper respiratory infections are not uncommon among the Tsimane (Eid et al., 2007). Together, these factors might place an 
upper limit on cardiovascular fitness, even for individuals engaged in frequent and intensive activity.

This study investigates senescent changes in cardiovascular fitness among a large sample of Tsimane adults and tests whether predicted factors described above mediate these changes. To explore differences between subsistence groups and industrialized nations, Tsimane values are compared with data from the Canadian Health Measures Survey, which employed a similar method for measuring cardiovascular fitness. We first test whether Tsimane have higher peak $\mathrm{VO}_{2} \max$ than Canadians. Second, we examine whether Tsimane show similar senescent declines as Canadians given demands on Tsimane for physical activity into older adulthood and increased stress on the cardiovascular system, which are expected to have opposing effects on fitness. Tsimane and Canadian performance is compared with previous work in industrialized and subsistence groups to provide additional context. Third, we examine the impact of mediating health and anthropometric factors on cardiovascular fitness, including anemia, respiratory illness, helminth infections, and proxy measures of market integration (distance to the local town, Spanish-speaking ability). Due to competing demands for somatic resources, we predict that indicators of poor health will predict lower physical fitness levels and faster age-related decline. Though other populations evidence lower levels of physical activity with increasing market integration, Tsimane living closer to town and those fluent in Spanish do not appear to become more sedentary (Gurven et al. 2013); we therefore expect that cardiovascular fitness will not differ between more and less market integrated individuals.

\section{Methods}

\section{Measuring cardiovascular fitness: maximal oxygen uptake}

Performance of the oxygen transport system can be measured by maximal oxygen uptake. Oxygen uptake (volume $\mathrm{O}_{2}$, or $\mathrm{VO}_{2}$ ) is calculated as the difference between the percentages of oxygen in inhaled (about 21\%) and exhaled gases, multiplied by the volume of gas exhaled (Howley et al., 1995). Maximal oxygen uptake $\left(\mathrm{VO}_{2} \mathrm{max}\right)$ refers to the peak oxygen uptake possible for a given individual, achieved during exercise to exhaustion. Because exercise to exhaustion can be potentially dangerous in individuals with significant underlying cardiovascular disease, $\mathrm{VO}_{2} \mathrm{max}$ is often estimated at a submaximal level of exercise (e.g., $85 \%$ of age-specific maximal heart rate, HR). Additionally, the use of a gas collection bag can be inconvenient or expensive for field and large scale projects (e.g., Shephard, 1970). For these reasons, estimation of $\mathrm{VO}_{2} \max$ from a participant's submaximal heart rate is often employed (e.g., Astrand and Ryhming, 1954). HR estimation methods were used for the Canadian and Tsimane samples, although only in the case of the Canadians was the routine for calculating $\mathrm{VO}_{2}$ max derived from laboratory studies with the same population.

\section{Study populations}

Tsimane-The Tsimane are a forager-horticulturalist group living in the Bolivian Amazon. The Tsimane have a population of $\sim 11,000$ spanning $90+$ villages ranging in size from 40 to 550 individuals. Villages near the local town (San Borja, population 24,000 ) or near roads 
have more extensive market access and greater participation in wage labor. Although PALs are often predicted to decline with market integration, Tsimane women and men living near the local town are not less active than Tsimane from other regions, perhaps because of the physical activity required in wage labor (e.g., logging and cash cropping; Gurven et al., 2013). Men in all regions have higher PALs than women, although men's activity exhibits more seasonal variation. Aging Tsimane remain active (Gurven et al., 2013), although these individuals may engage in less physically demanding subsistence activities because of increases in infirmity with age (Schniter, 2009).

Tsimane data were collected as part of the Tsimane Health and Life History Project (THLHP; http://www.unm.edu/ tsimane/) from 2002-2010. Patients were seen by THLHP physicians either during annual visits to villages or at the THLHP medical office in San Borja. Self-reported ailments were considered together with physical examination, fecal, and blood test results to assist in diagnosis and treatment. Sampling procedures for the exercise test were designed to ensure a sample representative of the Tsimane population. Participants' ages range from 10 to 88 years old ( $n=766 ; 55 \%$ female).

Pretest exclusion: Tsimane-Tsimane participants were not automatically excluded from the study for having a particular condition, but any complaints or conditions were recorded. Our study protocol did not exclude participants for any reason. However, some individuals who judged themselves unable to participate or who experienced discomfort during exercise opted out. The most common reason given by participants for opting out was pain, although this was rare (65 total excluded; remaining $n=701$ ). Nonparticipation rates in this population were below $10 \%$ until after age 70 (Supporting Information Fig. S1).

Although frailty may have constrained participation at late ages, the final sample below age 70 includes Tsimane at various levels of health and ability, allowing us to better explore the correlates of fitness decline (e.g., pain, infection) in this population. Pregnant and lactating women were included in the Tsimane sample, as women are pregnant or lactating for much of their adult lives.

Experimental protocol: Tsimane-Participants were asked to complete a modified submaximal Harvard step test (Astrand and Ryhming, 1954) at a bench height of $20 \mathrm{~cm}$ for 5 min at 30 ascents per minute (Walker and Hill, 2003). The pace of stepping was recorded for each participant regardless of whether the participant attained 30 steps per minute. $\mathrm{VO}_{2}$ max was estimated using Shephard's (1970) HR-based calculation routine for step tests. We first estimated $\mathrm{VO}_{2}$ with the following equation:

$$
\frac{\varepsilon(9.79 \times \mathrm{W} \times \mathrm{H} \times \mathrm{N})}{\mathrm{L}} \cdot \frac{1 k c a l}{4184 \text { Joules }} \cdot \frac{1 \mathrm{ml} O_{2}}{200 \mathrm{kcal}}
$$

where $W$ is weight in kilograms, $H$ is the step height in meters, $N$ is number of ascents during the exercise test, and $L$ is the length of the test in minutes. The conversion factor $\varepsilon$ adjusts for the efficiency of stepping. Stepping is about $16 \%$ efficient-only $16 \%$ of the work done during stepping contributes to vertical displacement (Shephard et al., 1976)—and thus work done must be multiplied by 6.69 (Shephard, 1970) to account for the amount of 
effort required by participants. The work (in Joules) required to complete the exercise test was calculated as $9.79 \mathrm{~m} / \mathrm{s}^{2} W \times H \times N$, where $9.79 \mathrm{~m} / \mathrm{s}^{2}$ is the acceleration due to gravity (Powers and Howley, 2009). Kilocalories per minute were divided by 200 to convert kilocalories to $\mathrm{ml} / \mathrm{min}$ of $\mathrm{O}_{2}$ (ACSM, 2006).

Equations for estimating $\mathrm{VO}_{2}$ max from submaximal $\mathrm{VO}_{2}$ at peak $\mathrm{HR}$ during the test $(P$; taken to be the last minute of exercise) were drawn from Shephard (1970). These are based on age and sex specific regressions that rely on assumptions about maximal HR by age.

$$
\begin{aligned}
& \text { Females : } \mathrm{E}\left(\mathrm{VO}_{2} \max \right)=\frac{\mathrm{VO}_{2}(198-72)}{\mathrm{P}-72} \cdot \frac{1 \mathrm{VO}_{2} \max }{0.0114 \text { age }+0.77} \cdot \frac{1}{k g} \\
& \text { Males : } \mathrm{E}\left(\mathrm{VO}_{2} \max \right)=\frac{\mathrm{VO}_{2}(198-61)}{\mathrm{P}-61} \cdot \frac{1 \mathrm{VO}_{2} \max }{0.0137 \mathrm{age}+0.668} \cdot \frac{1}{\mathrm{~kg}}
\end{aligned}
$$

The estimates of $\mathrm{VO}_{2}$ max produced by Eqs. 2a,b are in units of $\mathrm{ml}$ of oxygen per minute per kilogram $\left(\mathrm{ml} \mathrm{min}^{-1} \mathrm{~kg}^{-1}\right)$, also called relative $\mathrm{VO}_{2}$ max. Another common measure of $\mathrm{VO}_{2} \max$, absolute $\mathrm{VO}_{2} \max \left(1 \mathrm{~min}^{-1}\right)$, was calculated by multiplying $\mathrm{VO}_{2} \max$ in $1 \mathrm{~min}^{-1}$ $\mathrm{kg}^{-1}$ by participant body weight.

Post-test exclusion: Tsimane-The Shepard equations for estimating $\mathrm{VO}_{2}$ max depend on individuals achieving a heart rate within a certain range: $120-172$ for females, and 122170 for males. Typical protocols call for excluding individuals who do not meet this level. However, many Tsimane (55\% of females, $81 \%$ of males) did not achieve this criterion, either because the age-specific maximal HRs derived from industrialized populations are inaccurate for the Tsimane or because higher fitness allowed these Tsimane to perform the step test with less effort. We therefore evaluated several exclusion criteria for the Tsimane sample, including the HR range specified by Shephard (1970) for the calculation routine; a HR increase of $<5$ beats per minute during exercise (National Health and Nutrition Examination Survey, 2004); different percentages [65 (Siconolfi et al., 1985), 70 (American College of Sports Medicine, 2006; Canadian Society for Exercise Physiology, 2003), 75 (NHANES, 2004)] of age-specific maximal HR (Tanaka et al., 2001) achieved; the 95th centile obtained from a Generalized Additive Model for Location, Scale, and Shape (Rigby and Stasinopoulos, 2005); and a rate of HR increase from the beginning to the end of exercise that is beyond the $95 \%$ confidence interval (CI) from the 20 year age- and sexspecific mean. The sample size remaining after these exclusions varies, from $4 \%$ ( $75 \%$ of age-specific maximal HR) to $79 \%$ (increase $<5$ beats per minute during exercise) of our original sample (for sample sizes under each criterion considered, see Supporting Information Table S1). We interpreted exclusion criteria that excluded the vast majority of participants as not giving a representative sample of the Tsimane. The use of centiles or CIs enables us to compare each participant against a metric from the same population. Because the centile and $\mathrm{CI}$ approaches led to about the same, relatively small number of participants excluded, we adopted the CI exclusion for ease of interpretation. 
To evaluate the accuracy of HR estimation for the Tsimane population, we compare $\mathrm{VO}_{2}$ max estimated from $\mathrm{HR}$ with $\mathrm{VO}_{2}$ max estimated from the ratio of inhaled to exhaled $\mathrm{O}_{2}$ collected in a smaller subset of Tsimane. An additional strength of the $\mathrm{O}_{2}$ method is that the $\mathrm{VO}_{2}$ and $\mathrm{HR}$ measured for a given individual is extrapolated to predict their $\mathrm{VO}_{2} \mathrm{max}$ at their predicted age-specific maximal HR, without reliance on additional assumptions beyond that of an age-specific maximal HR. Methods used in $\mathrm{O}_{2}$ measurement are described in the Supporting Information (Appendix A).

Tsimane model covariates-Fat-free mass (FFM) was estimated by subtracting body fat mass from total mass. Body fat percentage was estimated with bioimpedance using a portable Tanita scale and with skinfold measurement taken at four sites (bicep, tricep, subscapular, suprailiac); body fat percentage was estimated from skinfold measurement with equations from Durnin and Womersley (1974). Arthritis and respiratory ailments were diagnosed by THLHP physicians during routine medical exams. Hemoglobin levels in $\mathrm{g} \mathrm{dl}^{-1}$ were attained using the QBC Auto-read Plus Dry Hematology System (QBC Diagnostics, Port Matilda, PA); anemia was defined using Centers for Disease Control (CDC) criteria (CDC, 1998) and, for ages for which CDC criteria were not available, World Health Organization (2001) criteria. Helminth and giardia infections were diagnosed in wet slide mounts and using a modified Percoll technique, as has been previously described (Blackwell et al., 2011; Eberl et al., 2002). We coded helminth infection as bivariate (presence or absence of helminths), combining diagnoses with hookworm, roundworm (Ascaris lumbricoides and Strongyloides stercoralis), and whipworm (Trichuris trichiura). Because of an established relationship between helminth infection and anemia, helminths and giardia are considered separately in this analyses. Self-reported pain was included as a binary measure indexing the presence of back, knee, bone, or connective tissue pain. Spanishspeaking ability was treated as dichotomous, where individuals rated as speaking more than "some" Spanish by THLHP project staff were considered Spanish speakers. Additional covariates include pregnancy status and as-the-crow-flies distance of home village to the market town of San Borja.

Because of a concern that leg length relative to bench height may affect performance during step tests (Shahnawaz, 1978), we considered including leg length in all within-population regressions. Leg length was calculated by subtracting participant seated height (minus chair height) from standing height. Including leg length worsened model fits, perhaps because mass and leg length are moderately correlated (for females, Pearson's $r=0.42$; for males, $r=$ 0.41 ) and mass is already controlled for by our use of relative (rather than absolute) $\mathrm{VO}_{2} \mathrm{max}$; additionally, use of the leg length variable eliminated participants for whom seated height data were unavailable. As such, we decided to not control for leg length in the analyses below.

Canadian health measures survey-Canadian fitness data were collected during the first wave of the Canadian Health Measures Survey (CHMS; www.statcan.gc.ca/imdb-bmdi/ 5071-eng.htm) from 2007 to 2009. Canadians were selected as a comparison group since $\mathrm{VO}_{2} \mathrm{max}$ in the CHMS was assessed using a step test procedure with $\mathrm{VO}_{2}$ max estimated based on HR. Individuals were sampled with the goal of representing $97 \%$ of the Canadian 
population from all provinces (Giroux, 2007). As measured with tri-axial accelerometers, Canadian children in this sample are sedentary for $64 \%$ of their waking hours (Colley et al., 2011a), adult (ages 20-79) females are sedentary for $69 \%$ of the day, and adult males are sedentary for $68 \%$ (Colley et al., 2011b).

Pretest exclusion: CHMS-CHMS participants were excluded from fitness testing if they had a heart condition, chest pain, high blood pressure (systolic blood pressure higher than 144) or heart rate (higher than 100), or were taking medication for any of these conditions (Bryan et al., 2007); across all ages, a total of $26.7 \%$ of potential participants were excluded, including 56\% of 60-69 year olds (Shields et al., 2010). Participants who experienced discomfort during testing could stop at any time. Women more than 12 weeks pregnant were not allowed to participate.

Experimental protocol: CHMS-Participants completed a step test developed by Bailey et al. (1976; modified by Weller et al., 1993) on a bench with two steps, each $20.3 \mathrm{~cm}$ tall. Individuals began stepping at a rate expected to require $65-70 \%$ of $\mathrm{VO}_{2} \mathrm{max}$ for a same-sex individual 10 years their senior (Canadian Society for Exercise Physiology, 2003). After a 3 min exercise interval, researchers measured HR to ascertain whether the participant had achieved $85 \%$ of his or her age-specific maximal HR. If $85 \%$ of maximal HR was reached, exercise testing was stopped; if $85 \%$ of maximal HR was not reached, participants proceeded to the next stage of exercise, stepping at a faster cadence.

$\mathrm{VO}_{2}$ max was estimated using a regression equation developed by Weller et al (1993):

$$
E\left(V O_{2} \max \right)=32+16 a-0.24 b-0.17 c
$$

where $a$ is the estimated $\mathrm{VO}_{2}$ at the end of the final stage of exercise (Weller et al., 1993), $b$ is age in years, and $c$ is body weight in $\mathrm{kg}$. If a participant could not step at the prescribed cadence during a given stage of exercise, $\mathrm{VO}_{2}$ max was estimated based on the last completed exercise stage (Shields et al., 2010). About 1\% of participants eligible for the test did not complete it. Participants did not proceed beyond the eighth level of exercise, regardless of whether they had attained $85 \%$ of their age-specific maximal HR. The result is estimated relative $\mathrm{VO}_{2} \max \left(\mathrm{ml} \mathrm{min}^{-1} \mathrm{~kg}^{-1}\right)$.

Skinfold measurements, used to calculate absolute FFM in this article, were taken before the cardiovascular fitness test at four sites (bicep, tricep, subscapular, and suprailiac) using Harpenden calipers (Baty International, UK; Shields et al., 2010), but only for individuals with a body mass index under $30 \mathrm{~kg} \mathrm{~m}^{-2}$.

\section{Statistical analyses}

All statistical analyses were performed with the R software package, version 2.15.3 ( $R$ Development Core Team, 2011). Smooth fits used generalized additive models (GAM), which regress a predictor on the response and smooth the residuals (Venables and Ripley, 2002); in the package used for the present analyses ( $m g c v$; Wood, 2006), the degree of smoothness was determined by a penalized likelihood technique. The result is a model that 
has both linear and non-linear elements, allowing a close fit to the data while also providing interpretable parameter estimates. Where appropriate, model fits were evaluated using the Akaike Information Criterion (AIC), a maximum likelihood measure of goodness-of-fit.

Exploratory models indicate sex differences in $\mathrm{VO}_{2} \mathrm{max}$ in the Tsimane population, and so each sex is modeled separately in all analyses. Because data for both populations only exist for ages 11-69, all cross-population comparative analyses (linear models, t-tests) are limited to this age group. Age in years is included in all analyses. Within-population comparisons (linear models) use the Tsimane subsample age 20 and older, an age group in which both males and females are close to their peak $\mathrm{VO}_{2} \mathrm{max}$, and include individuals up to age 70 , comparable to the Canadians and before the age at which opting out removed large portions of the sample. For the subsample between 20 and 69, females and males evidence a linear decline, although female $\mathrm{VO}_{2}$ max is curvilinear when all ages are considered; because all within-population comparisons (linear models) are performed on this subsample, age ${ }^{2}$ terms were not included. Publically available CHMS data are limited to $\mathrm{VO}_{2}$ max mean and standard deviation for age categories of variable size (for categories, see Table 3). Crosspopulation comparisons use the same age categories to explore differences between Canadians and Tsimane.

Covariates could not be included in between-population comparisons as the latter are based on binned data, however extensive individual-level Tsimane data allow for detailed examination of factors that may mediate physical fitness decline. For these withinpopulation linear models, we only included participants aged 20-69 for whom medical and anthropometric data were available during the same medical round (about a calendar year in length; Table 1).

To explore the possibility of a non-linear relationship between mass and $\mathrm{VO}_{2} \mathrm{max}$, and how this might affect any differences between the Tsimane and Canadians, we 1) allometrically scaled Tsimane $\mathrm{VO}_{2}$ max and 2) projected relative $\mathrm{VO}_{2}$ max for the Tsimane using Canadian fat mass and FFM from same-sex, same-age categories. To allometrically scale $\mathrm{VO}_{2} \mathrm{max}$, we calculated a, the scaling parameter in allometric equations, for the Tsimane (Calder, 1987). To project $\mathrm{VO}_{2}$ max for the Tsimane, assuming the same body composition as the Canadians, we regressed absolute $\mathrm{VO}_{2}$ max on absolute fat mass, absolute FFM, and age (and age ${ }^{2}$ for the Tsimane females) in the Tsimane female and male subsamples. With the resulting parameter estimates, we predicted whether Tsimane would perform at rates similar to those observed in our study if the Tsimane had the average fat mass and FFM exhibited in each of the four Canadian cohorts (ages: 12-19, 20-39, 40-59, and 60-79). The results of these calculations are discussed below. Hereafter, $\mathrm{VO}_{2} \max$ will refer to relative $\mathrm{VO}_{2} \max$ unless otherwise stated.

\section{Results}

\section{Age at peak $\mathrm{VO}_{2}$ max and levels across the lifespan}

Tsimane-Predicted values of absolute $\left(1 \mathrm{~min}^{-1}\right)$ and relative $\mathrm{VO}_{2} \max \left(\mathrm{ml} \mathrm{min}^{-1} \mathrm{~kg}^{-1}\right)$ for the Tsimane appear in Figure 1. Both Tsimane females and males exhibit a peak in absolute $\mathrm{VO}_{2}$ max. A peak in absolute $\mathrm{VO}_{2} \max$ is characteristic across populations but appears in late 
adolescence in industrialized nations, concurrent with peak absolute FFM (Armstrong, 2001). In the Tsimane as well, peak absolute $\mathrm{VO}_{2}$ max and peak absolute FFM are roughly concurrent: using smoothed fits of predicted values, female $\mathrm{VO}_{2}$ max peaks at age 31 at 2.95 $1 \mathrm{~min}^{-1}$ and absolute FFM at age 34 at $40.5 \mathrm{~kg}$; for males, $\mathrm{VO}_{2}$ max peaks at age 24 at 3.441 $\mathrm{min}^{-1}$ and FFM at age 29 at $54.4 \mathrm{~kg}$. Estimated peak $\mathrm{VO}_{2} \max$ is relatively robust to the smoothing parameter selected, with the peak shifting no more than 1 year for females and two years for males under different methods of smoothing. Average level of $\mathrm{VO}_{2}$ max may appear higher in females, but a median fit reveals that Tsimane females and males have roughly similar $\mathrm{VO}_{2} \max$ (see Supporting Information Fig. S2).

Relative ( $\mathrm{ml} \mathrm{min}{ }^{-1} \mathrm{~kg}^{-1}$ ) $\mathrm{VO}_{2}$ max estimation controls for the effect of body mass (and by extension, partially controls for percent FFM: correlation between the two for females, $r=$ -0.75 ; for males, $r=-0.43$ ). Removing the effects of body mass by using a relative measure does not remove the peaks exhibited by females or males in early adulthood (Fig. 1). Tsimane females peak at age $28\left(53.79 \mathrm{ml} \mathrm{min}^{-1} \mathrm{~kg}^{-1}\right)$ and Tsimane males peak at age 22 (at $54.89 \mathrm{ml} \mathrm{min}^{-1} \mathrm{~kg}^{-1}$ ). Indeed, this peak also remains when we scale by absolute FFM ( $\mathrm{ml} \mathrm{min}{ }^{-1}$ fat-free $\mathrm{kg}^{-1}$; see Supporting Information Table S2).

To evaluate whether Tsimane participants performed similarly under the $\mathrm{O}_{2}$ method, we compared age-matched subsamples to $\mathrm{O}_{2}$ method participants. Tsimane males performed significantly worse under the HR method relative to the $\mathrm{O}_{2}$ method $\left(\mathrm{O}_{2}\right.$ mean $=69.5 \mathrm{ml}$ $\min ^{-1} \mathrm{~kg}^{-1}, \mathrm{HR}$ mean $\left.=59.0 \mathrm{ml} \mathrm{min}^{-1} \mathrm{~kg}^{-1} ; t=6.29, P<0.001\right)$. There is no significant difference between Tsimane females tested under the HR and $\mathrm{O}_{2}$ methods $\left(\mathrm{O}_{2}\right.$ mean $=52.9$, HR mean $=54.3 ; t=-0.77, P=0.44)$. For a comparison of smooths from the two samples, see Supporting Information Figure S3.

Mediators of Levels Across the Tsimane Lifespan: We identified and investigated several health-related factors that might affect level of $\mathrm{VO}_{2}$ max achieved by either diminishing resources available to the body or hampering the cardiovascular system directly. We posit that these variables may mediate the effect of age on $\mathrm{VO}_{2}$ max. Candidate mediators include the presence of anemia, infection with helminths or giardia, arthritis or nonarthritic pain, respiratory ailments, distance from the local market town, and Spanish speaking ability.

Although percent FFM generally predicts absolute rather than relative $\mathrm{VO}_{2} \mathrm{max}$, we test it as a potential mediator. Pregnancy was included as a control in female models. While a high macroparasite load may increase the likelihood of having low hemoglobin (and thus anemia), an interaction term between presence of helminths and presence of anemia was not included because they are not significantly related in this sample: only 26 participants of the 92 with helminths have anemia, while 14 of the 86 without helminths have anemia (for females, $\chi^{2}=0.52, P=0.47$; for males, $\chi^{2}=2.00, P=0.16$ ).

To evaluate whether these candidate mediators affected $\mathrm{VO}_{2}$ max levels, we conducted linear regressions on relative $\mathrm{VO}_{2} \max$ (see Table 2). We first examined each predictor independently. Females with higher hemoglobin levels had significantly higher cardiovascular fitness performance: for an increase in $1 \mathrm{~g} \mathrm{dl}^{-1}$ concentration of hemoglobin, a Tsimane woman is predicted to have $2.93 \mathrm{ml} \mathrm{min}^{-1} \mathrm{~kg}^{-1}$ higher $\mathrm{VO}_{2} \max (t=2.68, P<$ 0.01). Helminth infection mediated the relationship between age and $\mathrm{VO}_{2} \mathrm{max}$ for males 
such that men with a helminth infection are predicted to have $6.16 \mathrm{ml} \mathrm{min}{ }^{-1} \mathrm{~kg}^{-1}$ higher $\mathrm{VO}_{2} \max (t=2.31 ; P<0.05)$. A best fit model approach (fit on the subset of females for whom all measures are available) provides similar results to fitting a separate model for each potential mediating variable. When a stepwise AIC procedure was used with data on all health and market integration measures, hemoglobin level was the only significant predictor that remained in the female model $(\mathrm{n}=82$; standardized $\beta=0.22, P<0.05)$. For males, helminth infection remained in the model as well $(n=116$; standardized $\beta=0.23, P<0.05)$.

Scaling $\mathrm{VO}_{2}$ max by FFM $\left(\mathrm{ml} \mathrm{min}{ }^{-1}\right.$ fat-free $\left.\mathrm{kg}^{-1}\right)$ rather than body mass produced similar results: hemoglobin levels remained a significant positive predictor of $\mathrm{VO}_{2} \mathrm{max}$ for females (standardized $\beta=0.30, P<0.01$ ) and helminth infection a positive predictor for males (standardized $\beta=0.20, P<0.05$ ). See Supporting Information Table $\mathrm{S} 3$ for all regression results with $\mathrm{ml} \mathrm{min}^{-1}$ fat-free $\mathrm{kg}^{-1}$ as the outcome.

Anemia was initially included in model fits, however treating hemoglobin level as a covariate in place of presence of anemia improved model fit for Tsimane females (anemia AIC $=1002.7$, hemoglobin AIC $=989.63$ ). Although no association was found between presence of anemia and helminth infection, there is a significant association between hemoglobin levels and helminth infection. Controlling for age, a helminth diagnosis is a significant negative predictor of hemoglobin levels for females (standardized $\beta=-0.31$, $P<0.01$ ). Replacing presence of anemia with hemoglobin level for males did not improve or worsen model fit, and there is no significant relationship between hemoglobin levels and helminth infection for males (standardized $\beta=-0.10, P=0.28$ ). Parameter estimates for anemia were not significant in models for either females or males.

Between-group-Table 3 presents Tsimane and Canadian estimated $\mathrm{VO}_{2}$ max binned into age categories used by CHMS. These data suggest that Canadian females and males achieve peak $\mathrm{VO}_{2}$ max between the ages of 11 and 14, while Tsimane males peak between ages 15 and 19. Tsimane females peak later, between age 20 and 39. Across comparable age categories, Tsimane have significantly higher $\mathrm{VO}_{2} \max$ than Canadians at all ages except between 11 and 15 for females, and 11 and 19 for males (Table 3). However, the sample size of Tsimane teenagers under age 15 is quite small. As aforementioned, to control for the influence of a small number of data points for the youngest and oldest Tsimane individuals, we used GAM to predict $\mathrm{VO}_{2}$ max across logged age. Predicted values suggest that Tsimane females peak at age 28 and Tsimane males peak at age 22 (see Fig. 1c, d). These estimates are consistent with scatterplots of the raw data (plotted on Fig. 1) and mask fewer finegrained effects of age than Table 3 , as each CHMS adult age category spans two decades.

It is possible the difference between the Tsimane and Canadians reflects a greater increase in body mass across ages in the Canadian population, or different trajectories of change in body composition. The former could occur because body mass appears in the denominator and can therefore scale down $\mathrm{VO}_{2}$ max, while the latter implies differential changes in FFM, when FFM is a predictor of $\mathrm{VO}_{2}$ max in many studies. To explore these possibilities, we performed two calculations: we allometrically scaled Tsimane $\mathrm{VO}_{2}$ max and we projected Tsimane $\mathrm{VO}_{2}$ max assuming the Tsimane had equivalent fat mass and FFM as Canadians from same-sex, same-age categories. Controlling for age, the allometric scaling coefficient a 
was slightly greater than 1 for both sexes (females, $a=1.11$; males, $a=1.18$ ). This suggests that any disparity in $\mathrm{VO}_{2}$ max between Canadians and the Tsimane cannot be explained solely by mass differences. Indeed, assuming the Tsimane have the same body composition as Canadians, projected $\mathrm{VO}_{2}$ max differs little from observed $\mathrm{VO}_{2}$ max. The Tsimane outperform the Canadians in every cohort by at least $3.5 \mathrm{ml} \mathrm{min}^{-1} \mathrm{~kg}^{-1}$, except among the youngest males who perform similarly (see Supporting Information Fig. S4).

To control for possible disparities in changes in body composition by age within each population, as these might also influence differences between the Tsimane and Canadians, we scaled $\mathrm{VO}_{2}$ max by absolute FFM from the same population to obtain $\mathrm{ml} \mathrm{min}^{-1}$ fat-free $\mathrm{kg}^{-1}$. Because Canadian body composition data were only available via skinfolds (bicep, tricep, subscapular, and suprailiac), we used the subset of Tsimane $(n=246)$ for which the same four skinfolds measurements were available. We calculated average absolute FFM for each cohort using average weight and average summed skinfolds (Durnin and Womersley, 1974) and scaled average $\mathrm{VO}_{2}$ max in $\mathrm{ml} \mathrm{min}^{-1}$ by this number to obtain $\mathrm{ml} \mathrm{min}^{-1}$ fat-free $\mathrm{kg}^{-1}$. Under this method of scaling, the Tsimane outperform Canadians in every cohort over age 20 by at least $1.65 \mathrm{ml} \mathrm{min}^{-1}$ fat-free $\mathrm{kg}^{-1}$ (see Supporting Information Table S2).

Canadian females and males in the 12-19 cohorts outperform Tsimane of the same age.

We next compared Tsimane to other subsistence populations reported in the literature (Table 4). Consistent with common practice in the literature, we report means for each group, but when possible, we also predicted $\mathrm{VO}_{2}$ max at age 25 to provide age-corrected comparisons. We selected age 25 as it is the age of peak relative $\mathrm{VO}_{2} \max$ in this study and for female Kamba and Maasai in Christensen et als. (2012) recent study. To predict $\mathrm{VO}_{2}$ max at age 25, we regressed the median ages on mean $\mathrm{VO}_{2}$ max across the available age categories. Tsimane females and males have roughly the same predicted $\mathrm{VO}_{2}$ max at age 25 as several other subsistence populations, but higher $\mathrm{VO}_{2} \max$ than industrialized populations. To test for differences between industrialized and subsistence populations, we conducted a linear regression on predicted $\mathrm{VO}_{2}$ max at age 25; this is not a meta-analysis, and results should be interpreted with caution. Overall, subsistence populations display higher peak $\mathrm{VO}_{2}$ max than in industrialized populations, controlling for sex (44.0 vs. $36.7 \mathrm{ml} \mathrm{min}^{-1} \mathrm{~kg}^{-1}[P<0.01]$ ). The Tsimane $\mathrm{O}_{2}$ and indigenous Siberian samples were excluded, Tsimane $\mathrm{O}_{2}$ to avoid the problem of non-independence with Tsimane HR data, and Siberians because the sample has a limited age range compared with the other studies.

\section{Pace of decline: slope of $\mathrm{VO}_{2}$ max decline across the lifespan}

Tsimane-To evaluate whether Tsimane participants performed similarly under different methods, we compared age-matched subsamples of participants from the present study with $\mathrm{O}_{2}$ method participants. Despite a higher level (intercept) of $\mathrm{VO}_{2} \max$ in the $\mathrm{O}_{2}$ sample, Tsimane males declined marginally significantly faster under the $\mathrm{O}_{2}$ method relative to the HR method $\left(\mathrm{O}_{2}=6.8 \%\right.$ per decade, $\mathrm{HR}=4.7 \%$ decline per decade; $\left.t=-1.95, P=0.05\right)$. There is no significant difference between Tsimane females tested under the $\mathrm{O}_{2}$ and HR methods $\left(\mathrm{O}_{2}=6.0 \%\right.$ per decade, $\mathrm{HR}=4.8 \%$ decline per decade; $\left.t=-0.55, P=0.58\right)$. Mediators of Slope Across the Lifespan. We fit a series of linear models to test for interactions between the candidate mediators and age-related decline in $\mathrm{Tsimane} \mathrm{VO}_{2}$ max. There are no variables 
that significantly interact with age to predict $\mathrm{VO}_{2} \mathrm{max}$ (see Supporting Information Table S4). An AIC selection approach and scaling by absolute FFM (see Supporting Information Table S3) provides the same results: no variables significantly interact with age to predict $\mathrm{VO}_{2} \max$.

Between-group $-\mathrm{VO}_{2} \max$ is most often reported as a linear decline across the adult lifespan, though Hawkins and Wiswell (2003) dispute whether the decline is actually linear. For example, a linear approximation is not appropriate for Tsimane females if ages 11-80 are considered. Figure 2 contrasts linear declines in $\mathrm{VO}_{2} \max$ for Canadians and Tsimane males, as well as a curvilinear fit for Tsimane females, with declines in industrialized nations derived from meta-analyses (Fitzgerald et al., 1997; Wilson and Tanaka, 2000). To explore whether rates of decline in $\mathrm{VO}_{2} \mathrm{max}$ among Tsimane and Canadians were different, we regressed average $\mathrm{VO}_{2}$ max by age category on median age (for a given age category), population, and their interaction term. For comparability, Tsimane were binned into the Canadian age categories and averages were computed for these categories, leading to estimated declines slightly different from those in Table 4; for the purposes of this test, we treat the Tsimane female decline as linear. Because within-population variance in decline is not available, these regressions should be treated as descriptive comparisons rather than statistical tests of differences between the two groups. The rate of decline in $\mathrm{VO}_{2} \max$ is steeper for Canadian females (6.9\% per decade faster decline per decade) and males (4.2\% faster decline per decade) compared with Tsimane females and males.

The rate of cardiovascular fitness decline between the Tsimane and Canadians is different, but this difference does not extend to industrialized and subsistence populations (see Table 4). Controlling for sex, subsistence groups have about one quarter of a percent lower declines per decade. Again, because the variance in decline is not represented in this regression, results should be interpreted as comparative rather than as a statistical test. As before, Tsimane $\mathrm{O}_{2}$ results were not included in the analysis to avoid nonindependence, and the indigenous Siberians were excluded because of discrepancy in ages sampled.

\section{Discussion}

Our comparisons demonstrate that across a wide variety of societies, cardiovascular fitness senesces with age. Cardiovascular fitness is higher on average among members of subsistence societies than among industrialized societies, but rates of fitness decline from peak are not slower. Our more detailed comparison between the Tsimane, a subsistence population, and Canadians, an industrialized population, reveals differences in cardiovascular fitness levels and rate of fitness decline. Cardiovascular fitness levels were higher among the Tsimane than among Canadians, and the rate of decline across the lifespan was significantly slower among Tsimane women and men. Potential Canadian participants were excluded due to many health concerns, including pregnancy and history of high blood pressure, whereas Tsimane were only excluded if they self-identified as unable to participate. This suggests the Canadian sample is a relatively healthy subsample of Canada, yet the Tsimane still outperform them in cardiovascular fitness. It may be that the higher demand for cardiovascular fitness in late ages among the Tsimane outweighs any effects of poor health. Another possibility is that greater self-selection among Tsimane due to higher 
adult mortality leaves more robust older adult survivors, thereby reducing the observed slope of fitness decline at the population level (Vaupel et al., 1979); perhaps this is partially why fewer Tsimane older adults opted out of the exercise test than Canadian older adults were screened out (ages 60-69; Canadian females $=56 \%$, Tsimane females $=15 \%$; Canadian males $=57 \%$, Tsimane males $=5 \%$ ).

Consistent with prior research on age-related changes in cardiovascular fitness, the Tsimane do evidence a linear decline in $\mathrm{VO}_{2}$ max with age, but not as steep a decline as typically seen in industrialized populations. Based on comparisons with the Canadians and with other industrialized populations, we believe the Tsimane data from the present study and the pilot $\mathrm{O}_{2}$ data combined indicate that the Tsimane perform better on tests of cardiovascular fitness than the average individual from an industrialized nation.

To further explore the potential effects of health factors on cardiovascular fitness level and rate of decline, we investigated predictors of individual differences in fitness within the Tsimane population. Overall, we found that most health indicators among the Tsimane did not hinder $\mathrm{VO}_{2}$ max levels or rates of decline. Lower hemoglobin levels were associated with lower $\mathrm{VO}_{2}$ max levels in women, but not men, consistent with the notion that compromised blood oxygen transport curbs cardiovascular fitness (Buzina et al., 1989; Panter-Brick et al., 1992). In the US, low hemoglobin is more common in active women than active men (Sinclair and Hinton, 2005); hemoglobin is also lower in Tsimane women than Tsimane men (female $=12.9$ [s.d. 1.3] $\mathrm{g} \mathrm{ml}^{-1}$, males $=14.2[1.3] \mathrm{g} \mathrm{ml}^{-1}$ ). Even mild (non-anemic) iron deficiencies impacts women's exercise performance (Zhu and Haas, 1997). Inconsistent with findings from Panter-Brick et al. (1992) among rural Nepalese, helminth infection did not diminish levels of $\mathrm{VO}_{2} \mathrm{max}$; for Tsimane men, helminth infection was actually a predictor of higher $\mathrm{VO}_{2} \max$. There are several reasons why this might be the case. First, we only tested whether presence or absence of helminths mediated the effect of age on $\mathrm{VO}_{2}$ max, rather than parasite load (e.g., number of worms, egg counts): it is possible that helminth infection only affects $\mathrm{VO}_{2}$ max at high parasite loads. Second, blood loss (and thus low hemoglobin levels) resulting from helminth infection may be partially offset by the amount of iron in the Tsimane adult diet. Tsimane iron intake is an estimated $166 \%$ of the U.S. Dietary Reference Intake (Martin et al., 2012) and Tsimane hemoglobin levels are higher than in the Nepalese (females: 12.9 vs. 10.9; males 14.24 vs. 12.0; Panter-Brick et al., 1992). Third, these analyses consider helminth infection at the time of exercise test rather than past infections. It may be that the cumulative burden of past infection has a larger effect on cardiovascular fitness; if so, this would suggest that the surprising, positive effect of helminth infection on $\mathrm{VO}_{2}$ max levels in men is either spurious or capturing a third variable.

Secular declines in $\mathrm{VO}_{2}$ max are expected with increasing market integration and lifestyle change because of increased sedentism (Katzmarzyk et al., 1994; Rode and Shephard, 1994). Two proxies for market integration in this population-distance to San Borja and the ability to speak Spanish-were not significant predictors of $\mathrm{VO}_{2}$ max levels or decline. This is consistent with our predictions, as Tsimane females and males that live near town do not appear to have lower activity levels (Gurven et al., 2013). Wage opportunities near town primarily include working as ranch hands, collecting and weaving palm thatch panels, cash cropping, and working for logging companies. Each of these involves extensive activity; 
furthermore, transportation to town often involves bicycling, walking, and poling dugout canoes. Cash cropping of rice and corn also involves the clearing and weeding of larger fields. Except for cash cropping and palm thatch manufacture, most wage labor opportunities are currently restricted to men.

This study makes several unique contributions to the existing literature. It offers the first systematic comparison of cardiovascular fitness level and rate of decline between subsistence and industrialized societies. Results compiled from previous studies support the general claim that despite greater pathogen stress, the greater activity regime of subsistence societies helps support higher peak $\mathrm{VO}_{2} \mathrm{max}$. Additionally, this is one of the first studies to explore senescent changes in cardiovascular fitness within a large sample from a subsistence population. The large number of health measures and proxies of market integration available permitted testing whether these factors mediated age-related variation, and whether they modulated the rate of decline. Despite reports that health status and market integration have been important in other studies (e.g., Buzina et al., 1989; Katzmarzyk et al., 1994; PanterBrick et al., 1992; Rode and Shephard, 1994), their overall net effect was small among the Tsimane, most apparent in measures of hemoglobin levels among women and helminth infection among men.

The results of these analyses may also shed light on individual and population level differences in chronic disease. In industrialized populations, meta-analyses demonstrate that cardiovascular fitness is protective against cardiovascular disease (Jette et al., 1992; Hawkins and Wiswell, 2003). Prior studies among Tsimane suggest relatively few deaths from heart attacks or strokes (Gurven et al., 2007); a low prevalence of common cardiovascular disease risk factors, like obesity, high blood low-density lipoprotein levels, hypertension, and peripheral arterial disease; and the existence of additional protective factors like lean diet and physical activity (Gurven et al., 2009, 2013; Vasunilashorn et al., 2010). Market foods such as cooking oil, sugar, and pasta represent only $6 \%$ of the average Tsimane diet, and Tsimane also consume a great deal of lean meat and omega-3 fatty acids (Martin et al., 2012). This study complements these findings by demonstrating that Tsimane show relatively high $\mathrm{VO}_{2} \max$, an indicator of strong cardiorespiratory health. Tsimane $\mathrm{VO}_{2}$ max declines with age, as it does everywhere, which suggests declining muscle mass with age (Fleg and Lakatta, 1988) and lowered cardiac output (American College of Sports Medicine, 2006; Sagiv et al., 2007) rather than increased cardiovascular disease risk.

\section{Limitations}

The Canadians were selected as a comparison industrialized population because of the similarity of the CHMS and Tsimane protocols: very few studies of industrialized populations have large sample sizes, sample across the life course, and use a step test. Several aspects of the CHMS and Tsimane protocols remain potentially incomparable. The Canadians experienced more stringent exclusion criteria than the Tsimane, meaning that the Tsimane sample may be more representative of cardiovascular condition in the Tsimane population than the Canadian sample of the Canadian population. Again, if the Tsimane sample was subjected to these criteria, we might expect the differences in $\mathrm{VO}_{2}$ max between populations to only increase. On the other hand, Canadian participants were assigned 
stepping cadences based on their age and sex, and cadence was increased across the exercise test if a participant did not reach $85 \%$ of his or her age-specific maximal HR; all Tsimane were asked to complete 30 ascents per minute with no increase based on their achieved HRs. Few Tsimane reached $75 \%$ of their age-specific maximal HR (see Supporting Information Table S1), perhaps because the age-specific maximal HRs derived from industrialized populations are inaccurate for the Tsimane or because higher fitness allowed these Tsimane to perform the step test of 30 ascents per minute with less effort. Due to these discrepancies in protocol, which may lead to errors in estimating $\mathrm{VO}_{2} \mathrm{max}$, we also incorporated Tsimane data collected using the $\mathrm{O}_{2}$ method as a check, because the $\mathrm{O}_{2}$ method estimates $\mathrm{VO}_{2}$ max on the relationship between $\mathrm{HR}$ and $\mathrm{VO}_{2}$ in a given participant.

Indeed, it is an open question as to whether typical methods for indirectly estimating cardiovascular fitness from HR are appropriate for subsistence level populations. Common routines for $\mathrm{VO}_{2}$ max estimation assume age-specific declines in cardiovascular fitness (e.g., Shephard, 1970), but these methods have only been validated with samples from industrialized populations, which are often self-selected (Beall et al., 1985). Additionally, regressions drawn from laboratory studies require participants achieve a HR within a certain range for accurate $\mathrm{VO}_{2}$ max estimation; however, the appropriateness of these ranges given slight modifications to protocol and inclusion of participants of different ages, different populations, and both sexes is questionable. For example, the maximal HR exhibited by young men varies across subsistence populations (Shephard, 1978). Use of these criteria is complicated by the fact that the most commonly used equation for estimating maximal possible HR by age, 220-age, may be inaccurate (Robergs and Landwehr, 2002) and particularly inappropriate for older adults (see Tanaka et al., 2001). For these reasons, we chose to use an exclusion criterion for the Tsimane that evaluates individual increase in HR across exercise relative to the mean increase in HR for Tsimane of the same sex and age.

The pattern of Tsimane fitness decline differs moderately by the choice of exclusion criterion for participants (see Supporting Information Table S1) and by method of testing. However, this is a common finding. Lee et al. (2011) predicted $\mathrm{VO}_{2}$ max from submaximal exercise using the $\mathrm{O}_{2}$ method and the HR-based American College of Sports Medicine calculation routine in a US sample. They found that (1) the HR-based routine predicts higher $\mathrm{VO}_{2}$ max across the sexes than does the $\mathrm{O}_{2}$ routine, and (2) the two methods have a correlation of only 0.77 . When evaluating different testing procedures, Shephard et al. (1968) found differences in $\mathrm{VO}_{2}$ max estimation by type of test used (e.g., bicycle ergometer versus step test) and calculation routine. Exercise tests, exclusion criteria, and calculation routines combine to provide an estimate of actual $\mathrm{VO}_{2} \mathrm{max}$ for a given individual, and as such, variation in estimation is to be expected. However, such variation may affect crosspopulation comparisons in unforeseen ways, thus the comparisons presented here should be interpreted with caution.

While population-level variation in cardiovascular fitness decline may reflect the differences in the demands of endurance-based physical activity, muscularity, and compromised oxygen transport, it is possible that genetic factors may also play a potential role (Collins, 1999). In one industrialized sample, maternal cardiovascular fitness exhibited a heritability of $30 \%$, which is attributed to inheritance of the maternal mitochondrial genome (Bouchard et al., 
2000). We do not have the relevant genetic data for the populations considered here, however, and thus operate under the simplifying assumption that inheritance should not affect population-level patterns and will not consistently bias individual-level comparisons in any particular direction.

This study is further limited by its cross-sectional design. Cross-sectional data present wellknown problems for the measurement of individual aging (Crimmins and Seeman, 2001). Mortality selection, in which individuals in poorer condition are likely to die at younger ages, produces a downward bias in the estimation of aging rates at the individual level (Vaupel and Yashin, 1985; Vaupel et al., 1979). Cohort effects, if present, also produce complicated and non-monotonic biases in estimation (Carnes and Olshansky, 2001). Due to the problem of between-individual heterogeneity and the within-individual process of senescence, a recent overview of aging studies concludes that "only longitudinal studies [...] provide reliable sources of information in the study of senescence" (Nussey et al., 2008). To date there are no longitudinal studies of cardiovascular fitness in subsistence populations. We are currently re-testing participants under the $\mathrm{O}_{2}$ method, allowing a better grasp of the within-individual variation that shapes patterns of senescent decline.

\section{Supplementary Material}

Refer to Web version on PubMed Central for supplementary material.

\section{Acknowledgments}

The authors thank Paul Hooper, Steven Gaulin, John Tooby, Patricia Kramer, the Human Evolution and Biodemography laboratory, and the Center for Evolutionary Psychology at UCSB for helpful advice and feedback; the staff at the Tsimane Health and Life History Project; and the Tsimane for their participation and patience.

Contract grant sponsor: National Science Foundation (NSF); Contract grant number: BCS-0422690; Contract grant sponsor: National Institutes of Health/National Institute on Aging (NIH/NIA); Contract grant numbers: R01AG024119-01; R01AG024119-04; R01AG024119-07.

\section{Literature Cited}

American College of Sports Medicine. ACSM's Guidelines for Exercise Testing and Prescription. 7th. Philadelphia: Lippincott Williams \& Wilkins; 2006.

Armstrong N. Peak oxygen uptake in relation to growth and maturation in 11- to 17-year-old humans. Eur J Appl Physiol. 2001; 85:546-551. [PubMed: 11718283]

Astrand PO, Ryhming I. A nomogram for calculation of aerobic capacity (physical fitness) from pulse rate during submaximal work. J Appl Physiol. 1954; 7:218-221. [PubMed: 13211501]

Bailey DA, Shephard RJ, Mirwald RL. Validation of a self-administered home test of cardiorespiratory fitness. Can J Appl Sport Sci. 1976; 1:67-78.

Beall CM, Goldstein MC, Feldman ES. The physical fitness of elderly Nepalese farmers residing in rugged mountain and flat terrain. J Gerontol. 1985; 40:529-535. [PubMed: 4031400]

Bénéfice E, Ndiaye G. Relationships between anthropometry, cardiorespiratory fitness indices and physical activity levels in different age and sex groups in rural Senegal (West Africa). Ann Hum Biol. 2005; 32:366-382. Available from: http://www.ncbi.nlm.nih.gov/pubmed/16099780. [PubMed: 16099780]

Blackwell AD, Gurven MD, Sugiyama LS, Madimenos FC, Liebert MA, Martin MA, Kaplan HS, Snodgrass JJ. Evidence for a peak shift in a humoral response to helminths: age profiles of IgE in the Shuar of Ecuador, the Tsimane of Bolivia, and the U.S. NHANES. PLoS Negl Trop Dis. 2011; 
5:e1218. Available at: http://www.pubmedcentral.nih.gov/articlerender.fcgi? artid=3125146\&tool=pmcentrez\&rendertype=abstract. [PubMed: 21738813]

Blackwell AD, Martin M, Kaplan H, Gurven M. Evidence for an antagonistic relationship between Giardia lamblia and helminth infections: implications for treatment of helminth infections in developing populations.

Blair SN, LaMonte MJ, Nichaman MZ. The evolution of physical activity recommendations: how much is enough? Am J Clin Nutr. 2004; 79:913S-920S. Available at: http://www.ncbi.nlm.nih.gov/ pubmed/15113739. [PubMed: 15113739]

Bouchard C, Rankinen T, Chagnon YC, Rice T, Pérusse L, Gagnon J, Borecki I, An P, Leon aS, et al. Genomic scan for maximal oxygen uptake and its response to training in the HERITAGE Family Study. J Appl Physiol. 2000; 88:551-559. Available at: http://www.ncbi.nlm.nih.gov/pubmed/ 10658022. [PubMed: 10658022]

Bryan S, St-Denis M, Wojtas D. Canadian Health Measures Survey: clinic operations and logistics. Health Rep. 2007; 18:53-69. [PubMed: 18210870]

Buzina R, Bates CJ, van der Beek J, Brubacher G, Chandra RK, Hallberg L, Heseker J, Mertz W, Pietrzik K, et al. Workshop on Functional Significance of Mild-to-Moderate Malnutrition. Am J Clin Nutrition. 1989; 50:172-176.

Calder WA. Scaling energetics of homeothermic vertebrates: an operational allometry. Annu Rev Physiol. 1987; 49:107-120. [PubMed: 3551791]

Canadian Society for Exercise Physiology. The Canadian Physical Activity, Fitness \& Lifestyle Approach (CPAFLA): CSEP-Health \& Fitness Program's Health-Related Appraisal and Counselling Strategy. 3rd. 2003.

Carnes BA, Olshansky SJ. Heterogeneity and its biodemographic implications for longevity and mortality. Exp Gerontol. 2001; 36:419-430. Available at: http://www.ncbi.nlm.nih.gov/pubmed/ 11250115. [PubMed: 11250115]

Carrick-Ranson G, Hastings JL, Bhella PS, Shibata S, Fujimoto N, Palmer D, Boyd K, Levine BD. The effect of age-related differences in body size and composition on cardiovascular determinants of VO2max. J Gerontol A Biol Sci Med Sci. 2013; 68:608-616. Available at: http:// www.ncbi.nlm.nih.gov/pubmed/23160363. [PubMed: 23160363]

Centers for Disease Control and Prevention. Recommendations to Prevent and Control Iron Deficiency in the United States. MMWR Recomm Rep. 1998; 47:1-36. Available at: http://www.cdc.gov/ mmwr/preview/mmwrhtml/00051880.htm.

Centers for Disease Control and Prevention. Glossary of Terms. Physical Activity for Everyone. 2011. [Internet] Available from: http://www.cdc.gov/physicalactivity/everyone/glossary/

Christensen DL, Faurholt-Jepsen D, Boit MK, Mwaniki DL, Kilonzo B, Tetens I, Kiplamai FK, Cheruiyot SC, Friis H, et al. Cardiorespiratory fitness and physical activity in Luo, Kamba, and Maasai of rural Kenya. Am J Hum Biol. 2012; 24:723-729. Available at: http:// www.ncbi.nlm.nih.gov/pubmed/22836508. [PubMed: 22836508]

Colley RC, Garriguet D, Janssen I, Craig CL, Clarke J, Tremblay MS. Physical activity of Canadian children and youth: accelerometer results from the 2007 to 2009 Canadian Health Measures Survey. Health Rep. 2011a; 22:15-23. [PubMed: 21510586]

Colley RC, Garriguet D, Janssen I, Craig CL, Clarke J, Tremblay MS. Physical activity of Canadian adults: accelerometer results from the 2007 to 2009 Canadian Health Measures Survey. Health Rep. 2011b; 22:7-14. Available at: http://www.ncbi.nlm.nih.gov/pubmed/21510585. [PubMed: 21510585]

Collins KJ. Physiological variation and adaptability in human populations. Ann Hum Biol. 1999; 26:19-38. [PubMed: 9974081]

Crimmins, E.; Seeman, T. Cells and Surveys: Should Biological Measures be Included in Social Science Research?. Washington, D.C.: National Academy Press; 2001. Integrating Biology into Demographic Research on Health and Aging (With a Focus on the MacArthur Study of Successful Aging); p. 9-41.

Curran-Everett LS. Accordance Between VO2max and Behavior in Ngisonyoka Turkana. Am J Hum Biol. 1994; 6:761-771. 
Durnin JVGA, Womersley J. Body fat assessed from total body density and its estimation from skinfold thickness: measurements on 481 men and women aged from 16 to 72 years. Br J Nutr. 1974; 32:77-97. [PubMed: 4843734]

Eberl M, Al-Sherbiny M, Hagan P, Ljubojevic S, Thomas AW, Wilson RA. A novel and sensitive method to monitor helminth infections by faecal sampling. Acta Trop. 2002; 83:183-187. [PubMed: 12088860]

Eid, D.; Gurven, M.; Kaplan, H.; Winking, J. Aging in Developing Countries: Building Bridges for Integrated Research Agendas. Santiago, Chile: 2007. Enfermedades infecciosas a lo largo de la vida y en el envejecimiento en indígenas sudamericanos de la etnia Tsimane.

Ekblom B, Engström LM, Ekblom O. Secular trends of physical fitness in Swedish adults. Scand J Med Sci Sports. 2007; 17:267-273. Available at: http://www.ncbi.nlm.nih.gov/pubmed/17501867. [PubMed: 17501867]

Finch CA, Lenfant C. Oxygen Transport in Man. N Engl J Med. 1972; 286:407-415. [PubMed: 4550526]

Fitzgerald, MD.; Tanaka, H.; Tran, ZV.; Seals, DR. J Appl Physiol. Vol. 83. Bethesda, Md: 1997. Age-related declines in maximal aerobic capacity in regularly exercising vs. sedentary women: a meta-analysis; p. 160-165.1985Available at: http://www.ncbi.nlm.nih.gov/pubmed/9216959

Fleg JL, Lakatta EG. Role of muscle loss in the age-associated reduction in VO2max. J Appl Physiol. 1988; 65:1147-1151. [PubMed: 3182484]

Frisancho AR, Frisancho HG, Milotich M, Brutsaert T, Albalak R, Spielvogel H, Villena M, Vargas E, Soria R. Developmental, genetic, and environmental components of aerobic capacity at high altitude. Am J Phys Anthropol. 1995; 96:431-442. Available at: http://www.ncbi.nlm.nih.gov/ pubmed/7604895. [PubMed: 7604895]

Giroux S. Canadian health measures survey: sampling strategy overview. Health Rep. 2007; 18:31-36. [PubMed: 18210868]

Gurven M, Jaeggi AV, Kaplan H, Cummings D. Physical activity and modernization among Bolivian Amerindians. PLoS ONE. 2013; 8:1-13.

Gurven M, Kaplan H, Winking J, Rodriguez DE, Vasunilashorn S, Kim JK, Finch C, Crimmins E. Inflammation and infection do not promote arterial aging and cardiovascular disease risk factors among lean horticulturalists. PLoS ONE. 2009; 4:1-12.

Haidet GC. Dynamic exercise in senescent beagles: oxygen consumption and hemodynamic responses. The Am J Physiol. 1989; 257:H1428-1437. Available at: http://www.ncbi.nlm.nih.gov/pubmed/ 2589499.

Hawkins S, Wiswell R. Rate and mechanism of maximal oxygen consumption decline with aging: implications for exercise training. Sports Med. 2003; 33:877-888. Available at: http:// www.ncbi.nlm.nih.gov/pubmed/12974656. [PubMed: 12974656]

Hoffman, J. Physiological aspects of sport training and performance. 1st. Champaign, IL: Human Kinetics Publishers; 2002.

Hotez PJ, Bottazzi ME, Franco-Paredes C, Ault SK, Periago MR. The neglected tropical diseases of Latin America and the Caribbean: a review of disease burden and distribution and a roadmap for control and elimination. PLoS Negl Trop Dis. 2008; 2:e300. Available at: http:// www.pubmedcentral.nih.gov/articlerender.fcgi? artid $=2553488 \&$ tool $=$ pmcentrez $\&$ rendertype $=$ abstract. [PubMed: 18820747]

Howley ET, Bassett DR, Welch HG. Criteria for maximal oxygen uptake: review and commentary. Med Sci Sports Exerc. 1995; 27:1292-1301. Available at: http://www.ncbi.nlm.nih.gov/pubmed/ 8531628. [PubMed: 8531628]

Jetté M, Sidney K, Quenneville J, Landry F. Relation between cardiorespiratory fitness and selected risk factors for coronary heart disease in a population of Canadian men and women. CMAJ. 1992; 146:1353-1360. Available at: http://www.pubmedcentral.nih.gov/articlerender.fcgi? artid=1488567\&tool=pmcentrez\&rendertype=abstract. [PubMed: 1555164]

Katzmarzyk PT, Leonard WR, Crawford MH. Predicted maximal oxygen consumption of Indigenous Siberians. Am J Hum Biol. 1994; 6:783-790. 
King CH, Dickman K, Tisch DJ. Reassessment of the cost of chronic helmintic infection: a metaanalysis of disability-related outcomes in endemic schistosomiasis. Lancet. 2005; 365:1561-1569. Available at: http://www.ncbi.nlm.nih.gov/pubmed/15866310. [PubMed: 15866310]

Lee JM, Bassett D Jr, Thompson D, Fitzhugh E. Validation of the cosmed fitmate for predicting maximal oxygen consumption. J Strength Cond Res. 2011; 25:2573-2579. [PubMed: 21869633]

Madimenos FC, Snodgrass JJ, Blackwell AD, Liebert MA, Sugiyama LS. Physical activity in an indigenous Ecuadorian forager-horticulturalist population as measured using accelerometry. Am J Hum Biol. 2011; 23:488-497. Available at: http://www.pubmedcentral.nih.gov/articlerender.fcgi? artid=3110644\&tool=pmcentrez\&rendertype=abstract. [PubMed: 21538650]

Malina RM. Physical activity and fitness: pathways from childhood to adulthood. Am J Hum Biol. 2001; 13:162-172. Available at: http://www.ncbi.nlm.nih.gov/pubmed/11460860. [PubMed: 11460860]

Malina RM, Little BB. Physical activity: the present in the context of the past. Am J Hum Biol. 2008; 20:373-391. Available at: http://www.ncbi.nlm.nih.gov/pubmed/18433002. [PubMed: 18433002]

Manning JT, Morris L, Caswell N. Endurance running and digit ratio (2D: 4D): implications for fetal testosterone effects on running speed and vascular health. Am J Hum Biol. 2007; 19:416-421. [PubMed: 17420996]

Martin, Ma; Lassek, WD.; Gaulin, SJC.; Evans, RW.; Woo, JG.; Geraghty, SR.; Davidson, BS.; Morrow, AL.; Kaplan, HS., et al. Fatty acid composition in the mature milk of Bolivian foragerhorticulturalists: controlled comparisons with a US sample. Matern Child Nutr. 2012; 8:404-418. Available at: http://www.ncbi.nlm.nih.gov/pubmed/22624983. [PubMed: 22624983]

National Health and Nutrition Examination Survey. Cardiovascular Fitness Procedures Manual. 2004

Nussey D, Coulson T, Festa-Bianchet M, Gaillard JM. Measuring senescence in wild animal populations: towards a longitudinal approach. Function Ecol. 2008; 22:393-406.

Ogawa T, Spina RJ, Martin WHI, Kohrt WM, Schechtman KB, Holloszy JO, Ehsani AA. Effects of aging, sex, and physical training cardiovascular responses to exercise. Circulation. 1992; 86:494503. [PubMed: 1638717]

Panter-Brick C, Miller UG, Eggerman M. Hemoglobin levels and step test performance of men and women in Nepal. Am J Hum Biol. 1992; 4:481-491.

Pontzer H, Raichlen Da, Wood BM, Mabulla AZP, Racette SB, Marlowe FW. Hunter-gatherer energetics and human obesity. PLoS ONE. 2012; 7:e40503. Available at: http:/c/dx.plos.org/ 10.1371/journal.pone.0040503. [PubMed: 22848382]

R Development Core Team. R: A language and environment for statistical computing. R Development Core Team. 2011

Rigby R, Stasinopoulos D. Generalize additive models for location, scale and shape. Appl Stat. 2005; 54:507-554. with discussion.

Robergs RA, Landwehr R. The surprising history of the "HRmax5220-age" equation. J Exerc Physiol. 2002; 5:1-10.

Rode A, Shephard RJ. Physiological consequences of acculturation: a 20-year study of fitness in an Inuit community. Eur J Appl Physiol. 1994; 69:516-524.

Rowland TW, Boyajian A. Aerobic response to endurance training in children. Pediatrics. 1995; 96:654-658. [PubMed: 7567326]

Sagiv M, Ben-sira D, Amir R. What maintains energy supply at peak aerobic exercise in trained and untrained older men? Gerontology. 2007; 53:357-361. [PubMed: 17622751]

Sanada K, Kuchiki T, Miyachi M, Mcgrath K, Higuchi M, Ebashi H. Effects of age on ventilatory threshold and peak oxygen uptake normalised for regional skeletal muscle mass in Japanese men and women aged 20 - 80 years. Eur J Appl Physiol. 2007; 99:475-483. [PubMed: 17186296]

Schniter E. Why Old Age: Non-Material Contributions and Patterns of Aging Among Older Adult Tsimane'. 2009; 607

Shahnawaz H. Influence of limb length on a stepping exercise. J Appl Physiol. 1978; 44:346-349. [PubMed: 632174]

Shephard RJ. Computer programs for solution of the Astrand nomogram and the calculation of body surface area. J Sports Med. 1970; 10:206-210. 
Shephard RJ, Allen C, Benade AJS, Davies CT, Di Prampero PE, Hedman R, Merriman JE, Myhre K, Simmons R. Standardization of submaximal exercise tests. Bull World Health Organ. 1968; 38:765-775. Available at: http://www.pubmedcentral.nih.gov/articlerender.fcgi? artid=2554690\&tool=pmcentrez\&rendertype=abstract. [PubMed: 5303330]

Shephard RJ, Bailey Da, Mirwald RL. Development of the Canadian Home Fitness Test. Can Med Assoc J. 1976; 114:675-679. Available at: http://www.pubmedcentral.nih.gov/articlerender.fcgi? artid=1956906\&tool=pmcentrez\&rendertype=abstract. [PubMed: 56979]

Shields M, Tremblay MS, Laviolette M, Craig CL, Janssen I, Gorber SC. Fitness of Canadian adults: results from the 2007-2009 canadian health measures survey. Health Rep. 2010; 21:21-35. Available at: http://www.ncbi.nlm.nih.gov/pubmed/20426224. [PubMed: 20426224]

Siconolfi SF, Garber CE, Lasater TM, Carleton RA. A simple, valid step test for estimating maximal oxygen uptake in epidemiologic studies. Am J Epidemiol. 1985; 121:382-390. Available at: http:// www.ncbi.nlm.nih.gov/pubmed/4014128. [PubMed: 4014128]

Sinclair LM, Hinton PS. Prevalence of iron deficiency with and without anemia in recreationally active men and women. J Am Diet Assoc. 2005; 105:975-978. Available from: http:// www.ncbi.nlm.nih.gov/pubmed/15942552. [PubMed: 15942552]

Skinner JS, Gaskill SE, Rankinen T, Leon AS, Rao DC, Wilmore JH, Bouchard C. Heart rate versus \%VO2max: age, sex, race, initial fitness, and training response-HERITAGE. Med Sci Sports Exerc. 2003; 35:1908-1913. Available at: http://www.ncbi.nlm.nih.gov/pubmed/14600558. [PubMed: 14600558]

Sondik EJ, Madans JH, Gentlemand JF. Summary health statistics for U.S. adults: National Health Interview Survey, 2010. Vital Health Stat. 2012; 10:1-80. Available at: http:// www.ncbi.nlm.nih.gov/pubmed/20687424.

Stones, MJ.; Kozma, A. Aging and Human Performance. New York: Wiley; 1985. Physical performance; p. 261-292.

Tanaka H, Monahan KD, Seals DR. Age-predicted maximal heart rate revisited. J Am Coll Cardiol]. 2001; 37:153-156. Available at: http://www.ncbi.nlm.nih.gov/pubmed/11153730.

Vasunilashorn S, Crimmins EM, Kim JK, Winking J, Gurven M, Kaplan H, Finch CE. Blood lipids, infection, and inflammatory markers in the Tsimane of Bolivia. Am J Hum Biol. 2010; 22:731740. Available at: http://www.ncbi.nlm.nih.gov/pubmed/20721985. [PubMed: 20721985]

Vaupel JV, Manton KG, Stallard E. The impact of heterogeneity in individual frailty on the dynamics of mortality. Demography. 1979; 16:439-454. [PubMed: 510638]

Vaupel JW, Yashin AI. Heterogeneity's ruses: some surprising effects of selection on population dynamics. Am Stat. 1985; 39:176-185. [PubMed: 12267300]

Venables, WN.; Ripley, BD. Modern Applied Statistics with S. Fourth. New York: Springer; 2002.

Wagner PD. Determinants of maximal oxygen transport and utilization. Annu Rev Physiol. 1996; 58:21-50. Available at: http://www.ncbi.nlm.nih.gov/pubmed/8815793. [PubMed: 8815793]

Walker A, Arent SM, McKeever KH. Maximal aerobic capacity (VO2max) in horses: a retrospective study to identify the age-related decline. Comparative Exerc Physiol. 2010; 6:177-181. Available at: http://www.journals.cambridge.org/abstract_S1755254010000073.

Walker R, Hill K. Modeling growth and senescence in physical performance among the Ache of Eastern Paraguay. Am J Hum Biol. 2003; 208:196-208. [PubMed: 12621608]

Weller IM, Thomas SG, Corey PN, Cox MH. Prediction of maximal oxygen uptake from a modified Canadian aerobic fitness test. Can J Appl Physiol. 1993; 18:175-188. Available at: http:// www.ncbi.nlm.nih.gov/pubmed/8513290. [PubMed: 8513290]

Wilson TM, Tanaka H. Meta-analysis of the age-associated decline in maximal aerobic capacity in men: relation to training status. Am J Physiol Heart Circ Physiol. 2000; 278:H829-834. Available at: http://www.ncbi.nlm.nih.gov/pubmed/10710351. [PubMed: 10710351]

Wood, SN. Generalized Additive Models: An Introduction with R. Boca Raton, Florida: Chapman and Hall/CRC Press; 2006.

World Health Organization. Iron deficiency anaemia assessment, prevention, and control: a guide for programme managers. 2001. Available at: http://whqlibdoc.who.int/hq/2001/ WHO_NHD_01.3.pdf 
Yoopat P, Toicharoen P, Boontong S, Glinsukon T, Vanwonterghem K, Louhevaara V.

Cardiorespiratory capacity of Thai workers in different age and job categories. J Physiol Anthropol Appl Hum Sci. 2002; 21:121-128. Available at: http://www.ncbi.nlm.nih.gov/pubmed/12056179.

Zhu YI, Haas JD. Iron depletion without anemia and physical performance in young women. Am J Clin Nutr. 1997; 66:334-341. Available at: http://www.ncbi.nlm.nih.gov/pubmed/9250112. [PubMed: 9250112] 
A

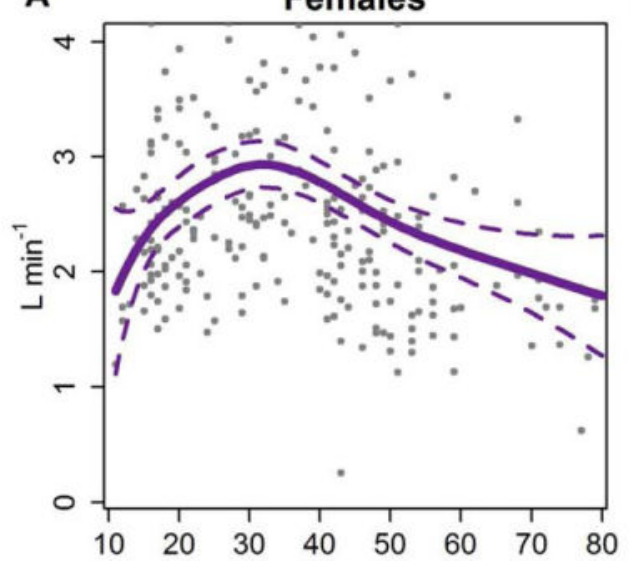

Females

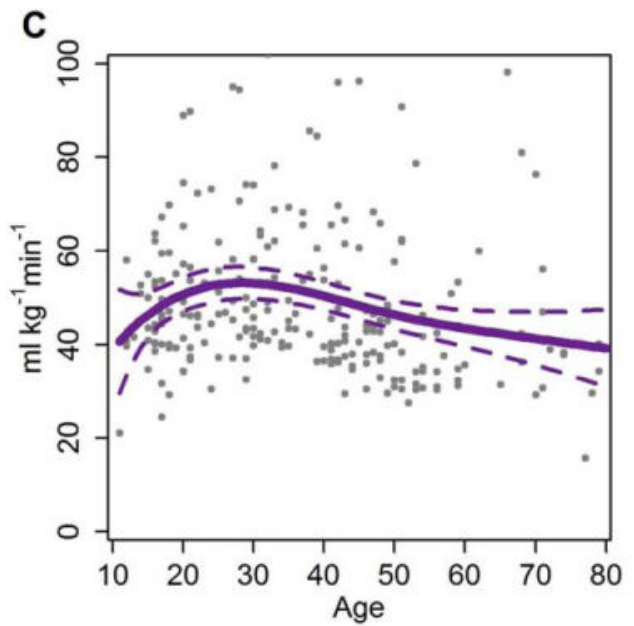

B

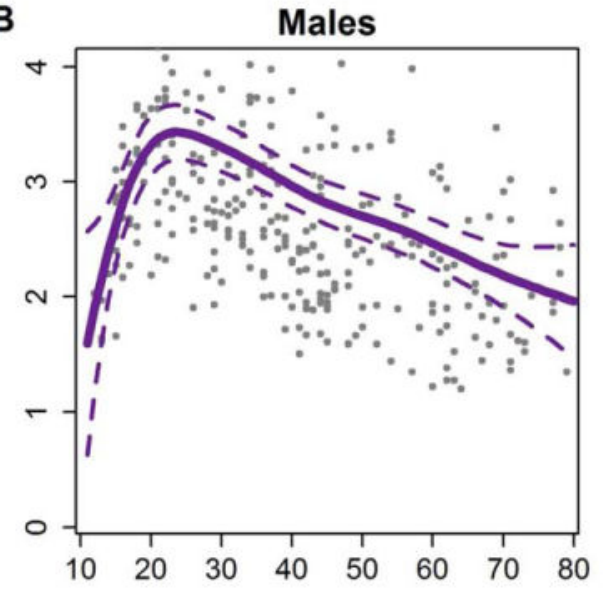

D

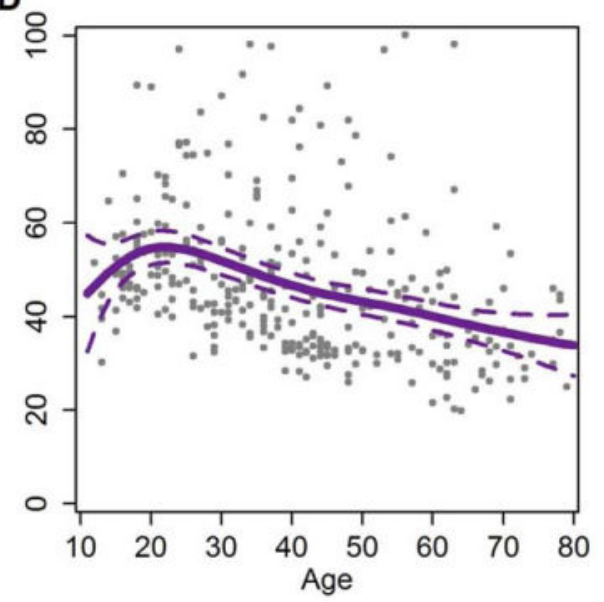

Fig. 1.

Predicted Tsimane $\mathrm{VO}_{2}$ max by age. Predicted values are drawn from GAM models regressing smooths of log age on $\mathrm{VO}_{2}$ max. Intervals are $95 \%$ prediction intervals. Age was smoothed using restricted maximum likelihood. Other smoothing parameters (such as Mallow's $\mathrm{Cp}$ and maximum likelihood) varied the age at peak absolute $\mathrm{VO}_{2} \max$ by up to 1 year for females and up to 2 years for males. Points represent the raw data for Tsimane. A: Absolute $\mathrm{VO}_{2}$ max by age for females. B: Absolute $\mathrm{VO}_{2}$ max by age for males. C: Relative $\mathrm{VO}_{2}$ max by age for females. $\mathrm{D}$ : Relative $\mathrm{VO}_{2}$ max by age for males. [Color figure can be viewed in the online issue, which is available at wileyonlinelibrary.com.] 

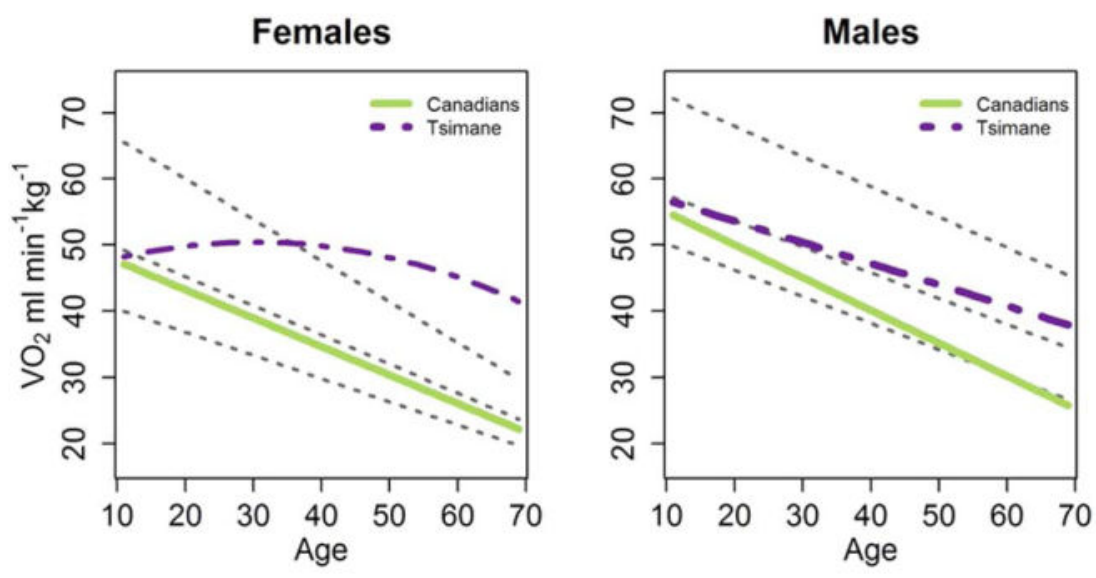

Fig. 2.

Linear changes in $\mathrm{VO}_{2}$ max with age for Canadians and the Tsimane. Intercepts and slopes for Canadians and Tsimane can be found in Table 4. Because age ${ }^{2}$ is significant for the full sample of Tsimane females, their change in $\mathrm{VO}_{2} \mathrm{max}$ across age is curvilinear. Slopes for endurance trained, active, and sedentary individuals from industrialized nations are drawn from a meta-analysis performed by Fitzgerald et al. (1997) for females, and Wilson and Tanaka (2000) for males. Endurance trained individuals are represented by the top dotted line above, followed by active individuals below and sedentary on the bottom. Trained individuals engage in 31 sessions of endurance exercise per week for at least a year, while active individuals engage in 2 or fewer sessions per week of cardiovascular exercise. [Color figure can be viewed in the online issue, which is available at wileyonlinelibrary.com.] 
Table 1

Descriptive statistics for the Tsimane after exclusion (ages 20-69)

\begin{tabular}{|c|c|c|c|c|}
\hline \multirow[b]{2}{*}{ Variables } & \multicolumn{2}{|l|}{ Tsimane Females } & \multicolumn{2}{|l|}{ Tsimane Males } \\
\hline & Mean (and S.D.) or Percent & $n$ & Mean (and S.D.) or Percent & $n$ \\
\hline Age & $41.3(14.3)$ & 203 & $43.6(15.2)$ & 280 \\
\hline Body weight (kg) & $53.4(9.3)$ & 203 & $62.4(7.4)$ & 280 \\
\hline FFM (kg) & $39.7(4.3)$ & 203 & $52.0(5.8)$ & 280 \\
\hline Perc. FFM & $0.75(0.08)$ & 203 & $0.84(0.05)$ & 280 \\
\hline Distance to town in $10 \mathrm{~km}$ & $4.4(2.4)$ & 196 & $4.2(2.4)$ & 273 \\
\hline Hemoglobin & $12.9(1.4)$ & 117 & $14.3(1.2)$ & 157 \\
\hline Arthritis & $11 \%$ & 133 & $4 \%$ & 185 \\
\hline Helminths & $51 \%$ & 92 & $58 \%$ & 128 \\
\hline Giardia & $38 \%$ & 92 & $40 \%$ & 128 \\
\hline Nonarthritic Pain & $54 \%$ & 133 & $75 \%$ & 138 \\
\hline Respiratory Ailments & $27 \%$ & 133 & $15 \%$ & 185 \\
\hline Spanish-speaking Ability & $17 \%$ & 271 & $42 \%$ & 271 \\
\hline Pregnant & $3 \%$ & 203 & - & - \\
\hline
\end{tabular}

Two-level factors are reported as percentage of the subsample with a given ailment. 


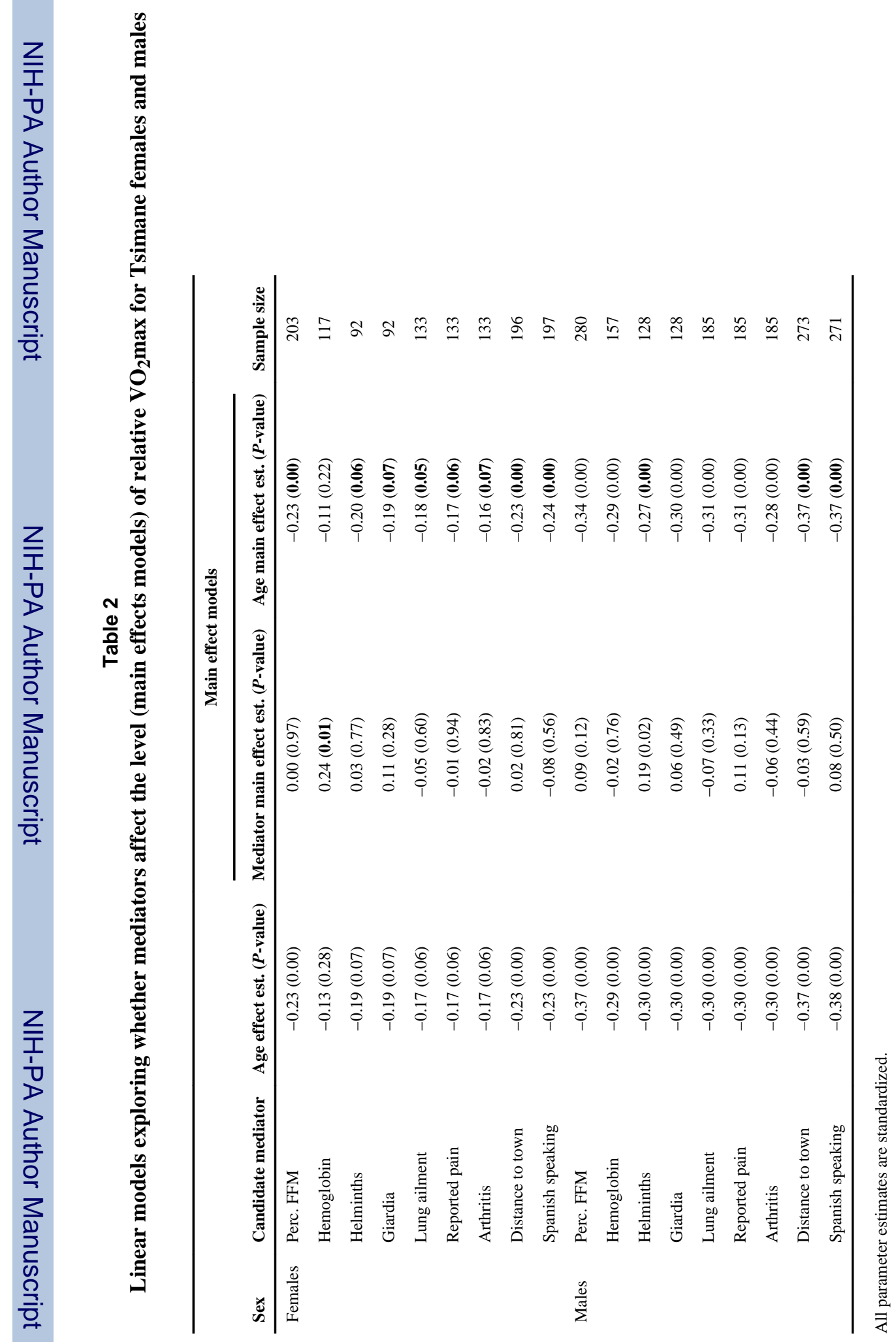




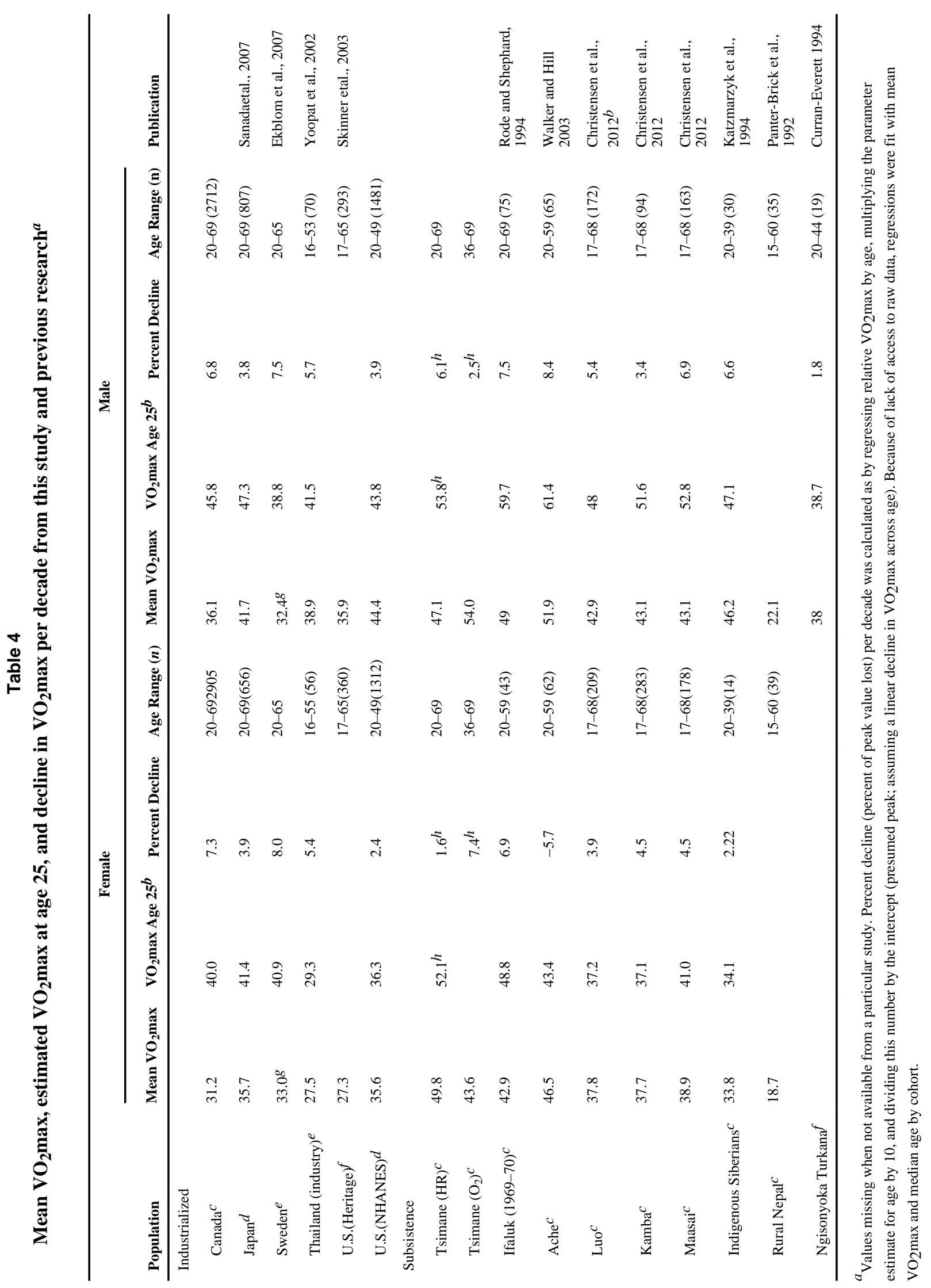




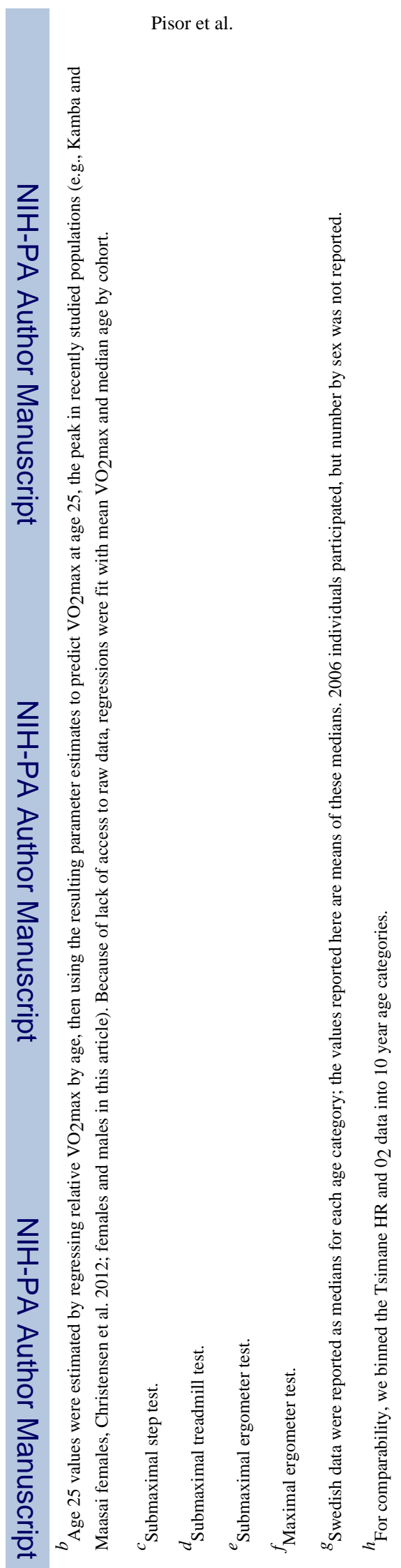

Am J Hum Biol. Author manuscript; available in PMC 2014 August 25. 